\title{
Primary intestinal lymphangiectasia co-existing with rotavirus infection. Who pulled the trigger for protein loss?
}

\author{
Erkan Dogan ${ }^{1}$; Eylem Sevinc ${ }^{2 *}$; Mehmet Akif Goktas ${ }^{3}$; Sadrettin Ekmen ${ }^{4}$ Nihal Yildiz ${ }^{4}$ \\ ${ }^{1}$ Assistant Professor, Medical School, University of Karabuk, and Pediatric Clinic Karabuk Training, Karabuk, Turkey \\ ${ }^{2}$ Associate Professor, Medical School, University of Karabuk, and Pediatric Gastroenterology, Karabuk, Turkey \\ ${ }^{3}$ Physician, Medical School, University of Erciyes, Kayseri, Turkey \\ ${ }^{4}$ Assistant Professor, Medical School, University of Karabuk, Turkey
}

\author{
*Corresponding Author(s): Eylem Sevinc \\ Karabuk University Faculty of Medicine, Balıklar Kayası \\ Mevkii, Demir Çelik Campus Karabuk, Turkey \\ Tel: +90-505-818-0588; \\ Email: dr.eylemsevinc@gmail.com
}

Received: Aug 31, 2018

Accepted: Oct 03, 2018

Published Online: Oct 05, 2018

Journal: Annals of Gastroenterology and the Digestive System Publisher: MedDocs Publishers LLC

Online edition: http://meddocsonline.org/

Copyright: (C) Sevinc E (2018). This Article is distributed

under the terms of Creative Commons Attribution 4.0

International License

Keywords: Lymphangiectasia; Enteropathy; Bowel disease

\section{Introduction}

Protein Losing Enteropathy (PLE) is a rare condition of severe protein loss from the intestine. PLE can be caused by a various disease such as Inflammatory Bowel Diseases (IBD), gastroenteritis, neoplasms, after fontan procedure and Primary Intestinal Lymphangiectasia (PIL). It can be due to congenital malformation of lymphatics or secondary to other causes such as malabsorption, chemotherapeutic, infectious, or retroperitoneal fibrosis [1]. The transient protein losing from intestine may ocur during rotavirus infection. However, the mechanism of protein loss in rota infection is not clearly understood [2]. Hereby we intend to report a case of an infant with PIL following rotavirus gastroenteritis.

\section{Abstract}

The protein loss from the digestive tract can result from many diseases, including inflammatory bowel disease, neoplasm, abnormalities of the lymphatic system, and infection such as tuberculosis, rotavirus. Primary intestinal lymphangiectasia is a rare protein-losing enteropathy caused by dilatation of lymph ducts in from the intestine. Differential diagnosis of protein losing enteropathy may be difficult in case of concurrent disorders of rotavirus infection and primary intestinal lymphangiectasy. Here we report the case of a 3-month-old male infant with protein-losing enteropathy caused by primary intestinal lymphangiectasia co-existing with rotavirus infection.

\section{Case report}

A 3-month-old Turkish male infant was admitted to hospital for diarrhea and failure to thrive. He was the first-born of nonconsanguineous parents, after 37 weeks gestation. Birth weight was $3350 \mathrm{~g}$. Until the age of 2 month the child had a normal growth and development. There was a history of watery and bloodless diarrhea, 8-10 times in a day. His general condition was poor because of dehydration. On physical examination, he presented with abdominal distention, hyperactive bowel sounds and generalized edema. 
Laboratory examinations revealed the following values: Total serum protein $2.8 \mathrm{~g} / \mathrm{dl}$ (5.7-8.2) and albumin $1.3 \mathrm{~g} / \mathrm{dl}$ (3.2-4.8). Serum electrolytes; potassium $3.1 \mathrm{mEq} / \mathrm{L}$ (3.5-5.5), sodium 131 $\mathrm{mEq} / \mathrm{L}$ (132-146), calcium $5.74 \mathrm{mEq} / \mathrm{L}$ (8.7-10.4), chloride 113 $\mathrm{mEq} / \mathrm{L}$ (99-109), magnesium 0.6 mEq/L (1.3-2.7). Blood analyses showed metabolic acidosis with $\mathrm{pH} 7.28$, and base excess-11.6 bicarbonate: $15.2 \mathrm{mmol} / \mathrm{L}$. On the day in stool examination rotavirus antigen test wa spositive. No bacteria was detected in the stool culture. At the third day of disease rotavirus antigen was not detected. Alpha-1 anti tripsin value was $4.5 \mathrm{mg} / \mathrm{g}$ (normal value<2.6) Eosinophilic cathionic protein was normal (16.1ng/ $\mathrm{mL}$ ). Serum total IgE and specific IgE levels were also in normal range. The elisa for $\mathrm{CMV}$ was negative. Abdominal ultrasound showed moderate ascites and fluid collection in the cavity of the tunica vaginalis of the testis. The doppler ultrasound and echocardiography were normal. However, during three weeks, he experienced worsening diarrhea, edema and the levels of hypoalbuminemia continued to be low. Upper gastrointestinal endoscopy was done and the duodenal biopsies obtained. On the endoscopy study whitish spots and snow flake appearance was seen on the duodenal mucosa (Figure 1). Duodenal biopsies revealed a dilated lymphatic ducts in submucosa (Figure 2).

The patient was started on dietary supplemantions such as basic-F Formula included high protein with Medium Chain Triglyceride (MCT)-enriched oil orally. As there was no change hypoalbuminemia and in diarrhea, we started him on octreotide sub cutaneous injections of $30 \mathrm{mcq}$ twice daily and periodical albumin infusions. In follow-up he is 6 months old and in an healthy condition at home. The weight was $7 \mathrm{~kg}$ (25 -50th percentile) and development was appropriate for age.

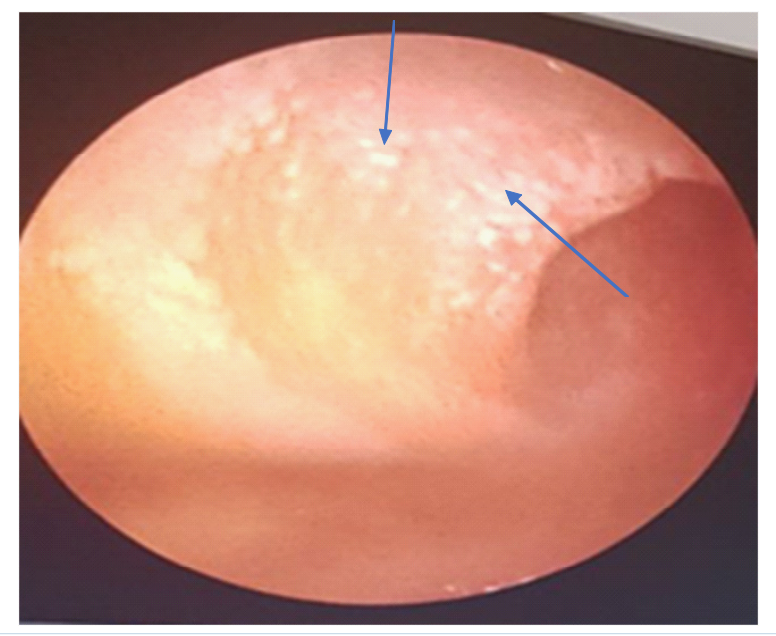

Figure 1: Endoscopic findings showing whitish spots (arrows) and snowflake appearance on the duodenal mucosa

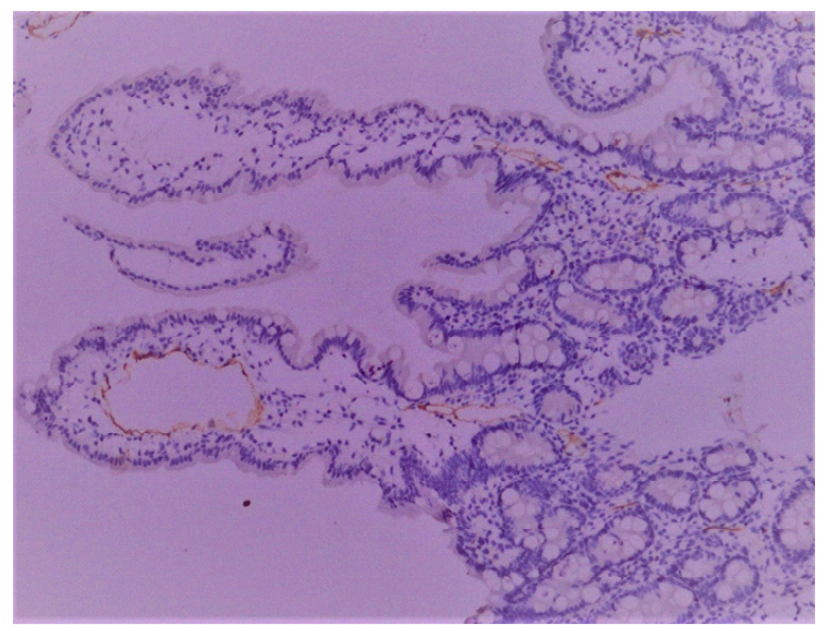

Figure 2: Microscopy showed dilated lymphaticducts (arrows) in thesubmucosa indicating intestinal lymphangiectasia; stained with D2-40 immunohistochemistry $\times 10$.

\section{Discussion}

PIL, also known as Waldmann's disease first described by Waldmann et al. in 1961. It is a rare disorder characterized by enlargement of the lymphvessels in the intestine. The enlargement of the lymph vessels results in lymph leakage into the intestine. PIL can present at any age, including the adolescent, typical cases often manifest in early childhood. Signs and symptoms of the PIL include diarrhea, vomiting, growth retardation, immunodeficiency and loss of lymphatic fluid into the intestines, which results in peripheral edema, ascites and hypogammaglobulinaemia [3]. In this case the patient presented with ascites, diarrhea and hypoalbuminemia.

Since intestinal lymphangiectasia can be primary or secondary, the diagnosis of PIL mustex clude the causes of secondary intestinal lymphangiectasia firstly. Endoscopic findings of intestinal lymphangiectasia include white frost or snowflakes in the mucosa. The diagnosis is confirmed by the intestinal biopsy that reveals the enlargement lymphatic lacteals and ducts [4]. In this case the snow flakes in the duodenal mucosa was seen and histologically, lymph lacteals dilation was observed.

The other diagnostic workup of the child with suspected PIL includes stool alpha-1-antitrypsin level measurement, lymphoscintigraphy and ultrasound. In this case we found stool alpha-1 -anti trypsin level was elevated. Lymphoscintigraphy may reveal absent or poorly developed lymphatics vessels [5]. However, lymphoscintigraphy could not be performed due to poor state of the patient.

PIL can be caused by mutations in PRG4 (proteoglycan 4) gene, FGFR3 (fibroblast growth factor receptor 3) gene and VEGFR3 (vascular endothelial growth factor receptor 3) gene. More overs omegenetic disorders are associated with PIL, including CHAPLE syndrome, Turner's syndrome, and Hennekam syndrome $[3,6]$. We could not carry out genetic study in our patients because of the lack of typical features of physical examination findings and funding issues.

Some disorders such as IBD, cow's-milk protein allergy and infections can mimic PLE [1]. How does rotavirus cause protein leakage in intestinal epithelia? The pathophysiology of PLE associated with rotavirus has not yet clarified. PLE due to rotavirus infection may be caused by several mechanisms, including the increased mucosal permeability, destruction of enterocytes, and the intestinal secretion stimulated by the proinflammatory cytokines from the rotavirus non-structural protein [2]. In 2011 Sulaiman et al. reported a child with transient PLE during rota virus infection [7]. Recently, Paris et al. reported an infant with rotavirus infection who presented with PLE [8]. In these reported cases, hypoalbuminemia was transient whereas in our patient had a persistent hypoalbuminemia after rotavirus infection, the PIL diagnosis is confirmed by the intestinal biopsy.

Treatment of PLE consists of octreotide, periodical bumin infusion, surgical intervention and dietary supplemantions such as high protein diet with supplement of fat-soluble vitamins and a low fat with MCT [9]. Ozekı et al. Proposed everolimus has a positive effect on disease course of PIL [10]. However we have not found out any study about the use of everolimus in children with PIL. The patient was treated with octreotide, periodic al- 
bumin infusion and dietary supplemantions included MCT and high protein diet with supplement of fat-soluble vitamins.

As a conclusion transiently protein loss is often found in rotavirus enteritis, suggesting the presence of PLE. In this instance, the diagnosis of PIL co-existing with rotavirus enteritis may be difficult. Endoscopic and histological findings may help in the differential diagnosis of PLE in case of a persistent hypoalbuminemia.

\section{References}

1. Fatemeh M, Mehri NS, Ahmad KT, Maryam M, et al. An Unusual Cause of Protein Losing Enteropathy in a 2.5-Year-Old Girl: Meso-Intestinal Fibrosis. Eur J Pediatr Surg Rep 2014; 1: 29-31.

2. Iwasa T, Matsubayashi N. Protein-losing enteropathy associated with rotavirus infection in an infant. World J Gastroenterol. 2008; 14: 1630-32.

3. Ozyurt A, Sevinc E, Baykan A, Arslan D, Argun M, Pamukcu O, et al. Variable clinical presentation in primary lymphoedema: Report of two cases. Clin Dysmorphol. 2014; 23: 83-7.

4. Ioannis X, Antigoni M, Evi S, Agathi T, Fotoulaki M, Kalambakas A. et al. Primary Intestinal Lymphangiectasia: Is It Always Bad? Two Cases with Different Outcome. Case Rep Gastroenterol. 2013; 7:153-63.

5. Vijay S, Srinath R, Deepanjali S, Chanaveerappa B, et al. Primary Intestinal Lymphangiectasia (Waldmann'sDisease) Presenting with Chylous Effusions in a 15-Year-Old. J ClinDiagn Res. 2017;11: OD17-18.

6. Malek NP, Ocran K, Tietge UJ, Maschek H, et al. A case of theyellow nail syndrome associated with massive chylousascites, pleural and pericardial effusions. Z Gastroenterol. 1996; 34: 763766.
7.

Bharwani SS, Shaukat Q, Basak R. A 10-month-old with rotavirus gastroenteritis, seizures, anasarca and systemic inflammatory response syndrome and complete recovery. BMJ Case Rep. 2011; 2011.

8. Parisi A, Cafarotti A, Salvatore R, Pelliccia P, et al. Protein-losing enteropathy in an infant with rotavirus infection. Paediatr Int Child Health. 2017; 1-4.

9. Isa HM, Ghadeer G, Mohamed AM. Intestinal lymphangiectasia in children A favorable response to dietary modifications. Saudi Med J. 2016; 37: 199-204.

10. Ozeki M, Tomohiro H, Kaori K, Norio K, et al. Everolimusfor Primary Intestinal Lymphangiectasia With Protein-Losing Enteropathy. Pedıatrics. 2016; 137: e 20152562. 